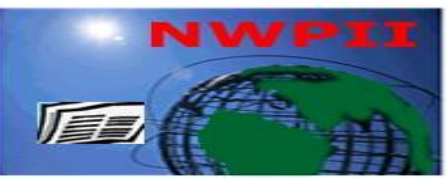

American Journal of Biomedical Sciences

ISSN: 1937-9080

nwpii.com/ajbms

\title{
Assessing the Possible Effect of Gamma Irradiation on the Reduction of aflatoxin B1, and on the Moisture Content in Some Cereal Grains
}

\author{
Neeven Fahmy Mohamed ${ }^{1}$, Rasha Said Shams El-Dine ${ }^{2 *}$, Metwally Aly Metwally Kotb ${ }^{2}$ \\ and Aida Saber ${ }^{1}$
}

\author{
${ }^{1}$ Nutrition Department, High Institute of Public Health, Alexandria University, Alexandria, Egypt \\ ${ }^{2}$ Medical Biophysics Department, Medical research Institute, Alexandria University, Alexandria, Egypt \\ "Corresponding Author \\ Rasha Said Shams El-Dine \\ Medical Biophysics Department \\ Medical research Institute \\ Alexandria University \\ Alexandria 2(03), Egypt \\ E-mail: Rasha_shams17@yahoo.com
}

Received: 8 December 2014; | Revised: 24 February 2015; | Accepted: 20 March 2015

\begin{abstract}
Aflatoxin $\mathrm{B}_{1}$ is the most potent hepatocarcinogen known in animals and it is classified by the International Agency of Research on Cancer (IARC) as Group I carcinogen meaning that it is a proven cancer-inducing agent. It also occurs in the environment contaminating a lot of different food and feed commodities. The aim of this study was to assess the possible effect of gamma irradiation on the reduction of aflatoxin $\mathrm{B}_{1}$ in some cereal grains and the impact on nutritive values including, ash, \&moisture. It was found that maize samples contain the highest level of aflatoxin $\mathrm{B}_{1}$ than wheat and rice. Gamma irradiation is a suitable technique which reduces the levels of aflatoxin $B_{1}$ in cereal samples without affecting the nutritive values, at $4 \mathrm{KGy}$ the reduction percents of aflatoxin $\mathrm{B}_{1}$ were $15.54 \%, 22.25 \%$, and $27.46 \%$ for maize, wheat, and rice respectively whereas at $6 \mathrm{KGy}$ the reduction percents of aflatoxin $\mathrm{B}_{1}$ were $32.39 \%, 43.84 \%$, and $56.38 \%$ respectively and the $8 \mathrm{KGy}$ radiation dose remove about $60.26 \%$ of the toxin in maize, $64.68 \%$ in rice and $69.29 \%$ in wheat samples. Higher radiation doses than $8 \mathrm{KGy}$ are required to remove the toxin until it reaches the legal limit (5ppb) according to FAO.
\end{abstract}

Keywords: Gamma Irradiation; aflatoxin B1; Cereal Grains; radiation.

\section{Introduction}

Hepatocellular carcinoma constitute $80 \%$ of cancer cases in developing countries as Egypt. The incidence of $\mathrm{HCC}$ is increasing, ranging between $3 \%$ and $9 \%$ annually depending on the location, and several other etiologic factors. e.g. hepatitis $\mathrm{B}$ and $\mathrm{C}$ virus infections. While $\mathrm{HBV}$ and HCV may account for the majority of HCC in Egypt, there is another factor including (e.g. aflatoxins, AF). $[1,2]$ Location and environmental 
condition in Egypt make it prone to aflatoxins. Studies suggest that aflatoxins are expected to spread and become more problematic with future climate conditions. There are many climatic reasons for an increase in aflatoxins, including an increase in temperature, humidity and moisture. [3]

Aflatoxins are a group of mycotoxins produced in tropical and sub-tropical regions.[4]. Aflatoxins are hepatic and carcinogenic secondary metabolities of moulds that produce mainly from Aspergillus flavus and Aspergillus paraciticus. Cereal grains are susceptible to aflatoxins. causing substantial losses of yield and frequently having a detrimental effect on grain quality.

This study aims to assess the possible effect of gamma irradiation on the reduction of aflatoxin $B_{1}$ in some cereal grains and the impact on nutritive values.

\section{Materials and Methods}

One group pre-post intervention design was conducted on 60 samples divided equally among the three different chosen cereals, wheat (Triticum aestivum L.), maize (Zea mays), and polished rice (Oryza sativa L). The minimal required sample units was calculated using STATA II software, precision $=10 \%, \alpha=0.05$, and was found to be 60 units.

Each sample unit was one kilogram; each kilogram was subdivided into equal four subgroups. The first sub-group was used as a control subgroup. The second sub-group was subjected to a gamma radiation dose of Cobalt- 60 of $4 \mathrm{KGy}$. The third sub-group was subjected to a gamma radiation dose of Cobalt- 60 of $6 \mathrm{KGy}$. The forth sub-group was subjected to a gamma radiation dose of Cobalt-60 of $8 \mathrm{KGy}$. All the sub-groups were stored in plastic bags at $4^{\circ} \mathrm{C}$ until analysis. All samples were subjected to chemical analysis to ensure their quality and safety for human consumption.

\section{Irradiation}

Maize, wheat, and rice seeds (250 g) subgroups were sealed in polyethylene plastic bags $(0.1 \mathrm{~mm}$ thickness) and irradiated at room temperature $\left(25^{\circ} \mathrm{C}\right)$ under ambient atmosphere.
The irradiation of samples carried out by using

${ }^{60}$ Co gamma ray (Indian irradiation unit) installed at the National Center for Radiation Research and Technology (NCRRT), Atomic Energy Authority, Egypt. All samples were exposed to a dose rate of $0.07 \mathrm{~Gy} / \mathrm{sec}$ at the time of the experiment.

\section{Aflatoxin $B_{1}$ determination by High Performance Liquid Chromatography (HPLC).}

$50 \mathrm{~g}$ of each ground sample was placed into ultraturrax and then $100 \mathrm{ml}$ of $60 \%$ acetonitrile/water (v/v) was added, and the mixture was stirred for $2 \mathrm{~min}$. at high speed. The extract was filtered through a Whatman No 3 filter paper and then through a microfibre filter. 2 $\mathrm{ml}$ of the final extract, corresponding to $1 \mathrm{~g}$ of the original material was diluted with $48 \mathrm{ml}$ of phosphate buffered saline (PBS, $\mathrm{pH} 7.4$ ) to give a solvent concentration of $2.5 \%$ or less (in order to protect the antibodies in immunoaffinity columns). The mixture was allowed to pass through a column contains monoclonal antibodies to aflatoxin bound to a solid support. By passing the diluted extract through the column any aflatoxin exists in the sample will bound to the antibody within the column. The column was then washed with $20 \mathrm{ml}$ of PBS. The elution of aflatoxin was done with $1.5 \mathrm{ml}$ of methanol and $1.5 \mathrm{ml}$ of pure water (it is a complete denaturation of monoclonal antibodies with the subsequent release of toxin into the solution). And samples were measured against standard at concentrations $0.05,0.1,1,5,10,20,50$, and 100 $\mathrm{ng} \mathrm{mL} \mathrm{mL}^{-1}$ per injection to estimate the linearity of the instrument.

\section{HPLC conditions}

$100 \mu \mathrm{l}$ of the each extract was injected in triplicate using C18 ODS (Octa Dodecyl Sulphate) reversed phase column $(250 \times 4.6 \mathrm{~mm}, 5$ $\mu \mathrm{m})$, Japan, heated to $40^{\circ} \mathrm{C}$. Mobile phase was water: methanol solution $(60: 40, \mathrm{v} / \mathrm{v})$, Flow rate 1 $\mathrm{ml} / \mathrm{min}$ and Ultra-violet detection of aflatoxin $\mathrm{B}_{1}$ at wavelength of $265 \mathrm{~nm}$ in (SPD-6AV UV-Vis detector, Shimadzu). 
II Determination of moisture content by method 44-15A of American Association of Cereal Chemists International (AACCI), onestage procedure ${ }_{.[5]}$

\section{Statistical analysis}

Data analyzed in triplicate, fed to the computer and analyzed using IBM SPSS software package version 20.0._Quantitative data were described using_mean and standard deviation. The given graphs were constructed using Microsoft excel software. Comparison between more than two populations was analyzed using F-test (ANOVA) and Post Hoc test (LSD). Significance of the obtained results was judged at the $5 \%$ level.

\section{Results}

Results expressed as mean \pm standard deviation of triplicate observations for each sample.

In this work three types of seeds were employed, namely, Maize, Wheat and Rice. Twenty samples of each type were used each of one kilogram, to study the effects of gamma irradiation on the aflatoxin $\mathrm{B}_{1}$ levels and the impact on nutritive values.

\section{Aflatoxin $B_{1}$ levels before exposure to Gamma radiation}

The distribution of aflatoxin $\mathrm{B}_{1}$ in cereal samples (maize, wheat, and rice) before exposure to different doses of gamma radiation.

Figure 1 illustrates the levels of aflatoxin $\mathrm{B}_{1}$ in maize, wheat, and rice before gamma-rays exposure.

Figure 2 represents a graphical comparison between aflatoxin $B_{1}$ levels in maize, wheat, and rice and the legal upper limit of aflatoxin $B_{1}$.

\section{Aflatoxin $B_{1}$ levels after exposure to different doses of Gamma radiation}

Table 1 describes the comparison between the alfatoxin $B_{1}$ levels in the different seeds samples before and after exposure to 4, 6, and 8 KGy gamma radiation.

Table 2 illustrates the reduction percents of aflatoxin $\mathrm{B}_{1}$ in the different samples after exposure to different radiation doses namely; 4KGy, $6 \mathrm{KGy}$, and $8 \mathrm{KGy}$.

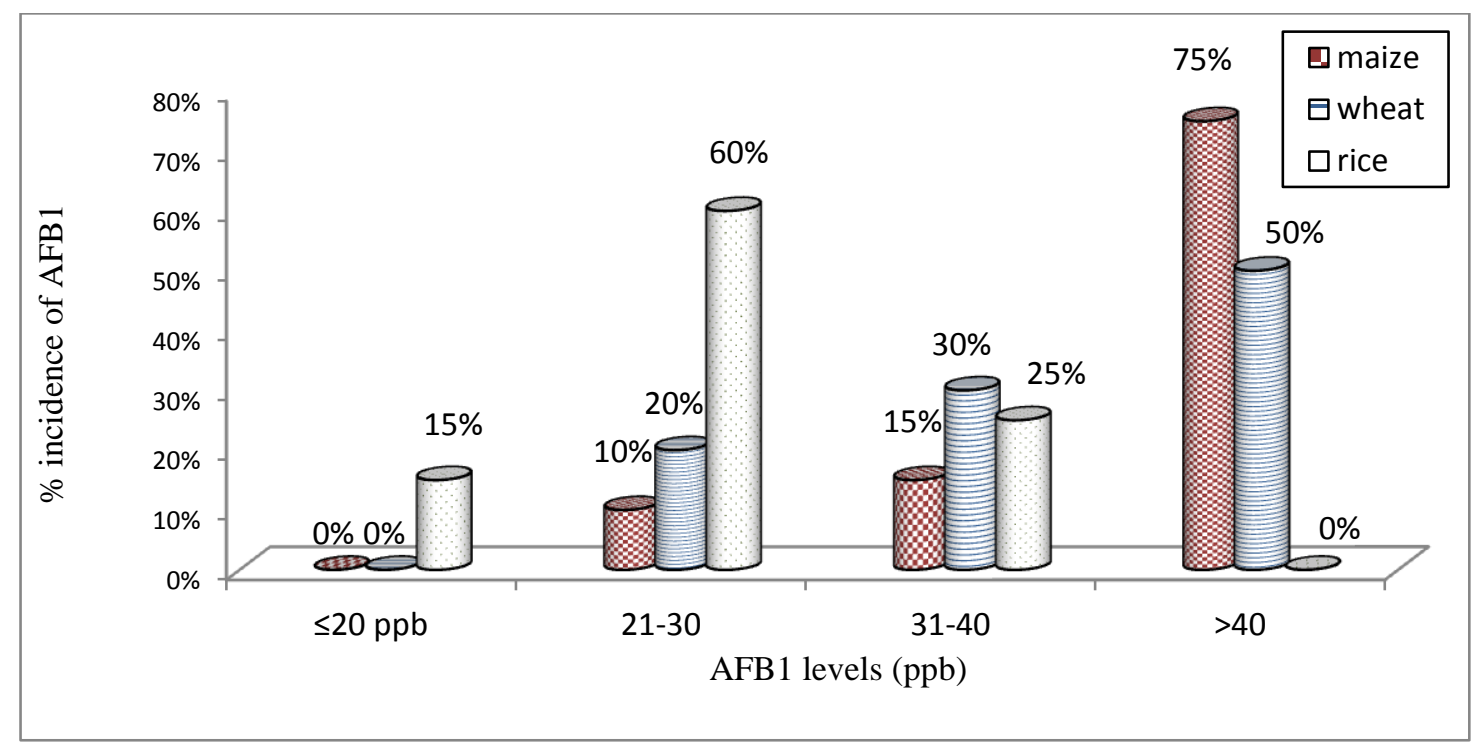

Figure 1. Distribution of aflatoxin $B_{1}$ in maize, wheat, and rice pre-irradiation 


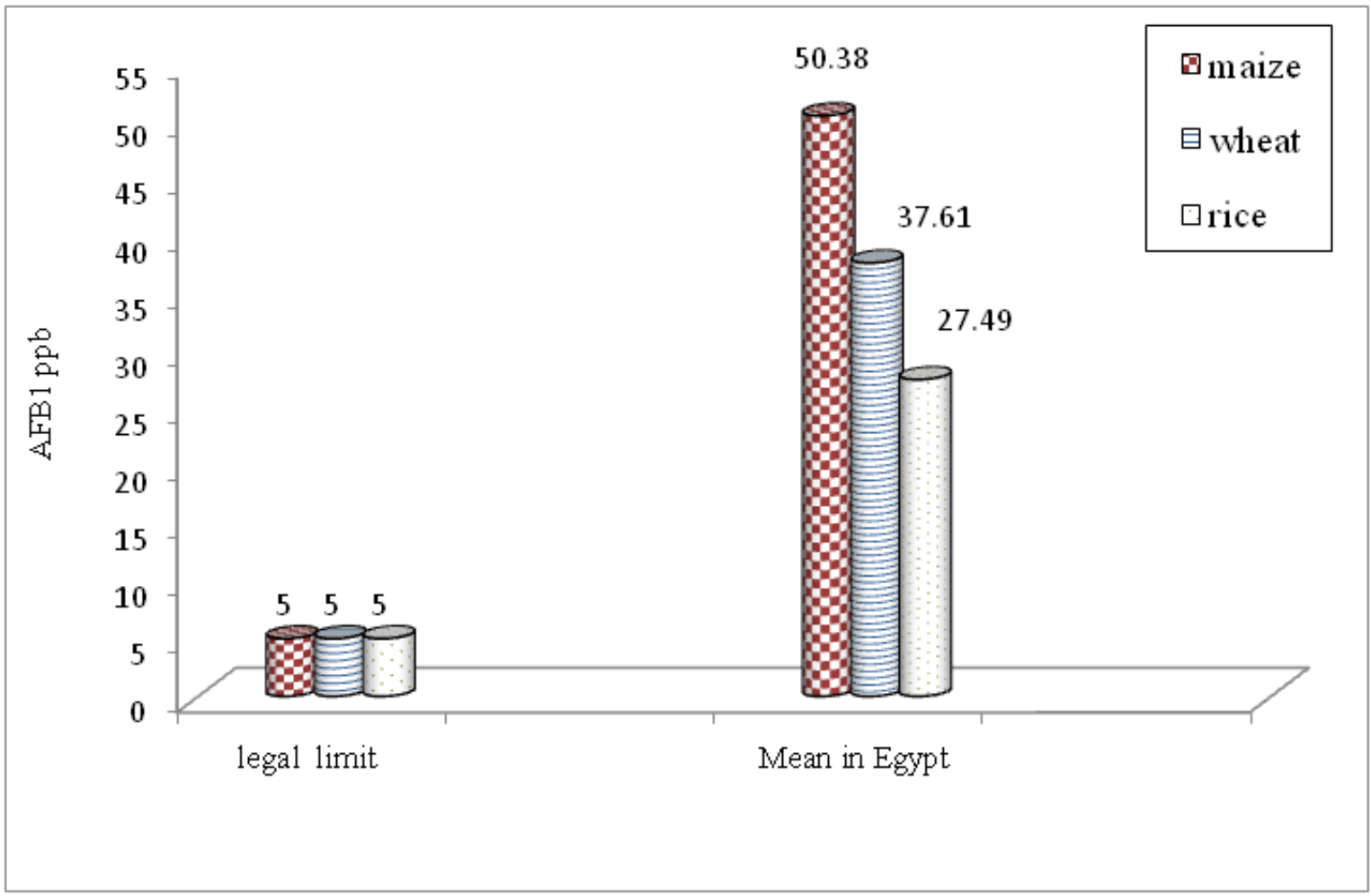

Figure 2. Aflatoxin $\mathrm{B}_{1}$ legal limit and aflatoxin $\mathrm{B}_{1}$ in Egypt.

Table 1: Comparison between different groups pre- and post-radiation according to aflatoxin $B_{1}$ levels (ng/g) in maize wheat and rice.

\begin{tabular}{|c|c|c|c|c|c|c||}
\hline \multirow{2}{*}{$\begin{array}{c}\text { Cereal } \\
\text { types }\end{array}$} & $\begin{array}{c}\text { Aflatoxin } \text { B }_{1} \\
\text { Pre-radiation } \\
\text { ng/g }\end{array}$ & \multicolumn{3}{|c|}{$\begin{array}{c}\text { Aflatoxin B } \\
\text { Post-radiation ng/g }\end{array}$} & \multirow{2}{*}{ F } & \multirow{2}{*}{ P } \\
\cline { 2 - 6 } & $\mathbf{0 ~ K G y}$ & $\mathbf{4 ~ K G y}$ & $\mathbf{6 ~ K G y}$ & $\mathbf{8 ~ K G y}$ & & \\
\hline Maize & $50.38^{\mathrm{a}} \pm 14.46$ & $42.55^{\mathrm{b}} \pm 13.04$ & $34.06^{\mathrm{c}} \pm 12.08$ & $20.02^{\mathrm{d}} \pm 6.70$ & $23.702^{*}$ & $<0.001^{*}$ \\
\hline Wheat & $37.61^{\mathrm{a}} \pm 6.85$ & $29.24^{\mathrm{b}} \pm 6.34$ & $21.12^{\mathrm{c}} \pm 6.54$ & $11.55^{\mathrm{d}} \pm 3.41$ & $70.182^{*}$ & $<0.001^{*}$ \\
\hline Rice & $27.49^{\mathrm{a}} \pm 7.32$ & $19.94^{\mathrm{b}} \pm 7.87$ & $11.99^{\mathrm{c}} \pm 7.34$ & $9.71^{\mathrm{c}} \pm 2.43$ & $18.834^{*}$ & $<0.001^{*}$ \\
\hline
\end{tabular}

Different superscripts are significant at $\mathrm{p} \leq 0.05$

F: F test (ANOVA)

*: Statistically significant at $\mathrm{p} \leq 0.05$

Results expressed as mean \pm standard deviation of triplicate observations for each sample

Table 2: Mean \%reduction of aflatoxin $B_{1}$ by different radiation doses at $4 \mathrm{KGy}, 6 \mathrm{KGy}, 8 \mathrm{KGy}$ in maize, wheat, and rice

\begin{tabular}{|c|c|c|c|}
\hline \multirow{2}{*}{ Cereal types } & \multicolumn{3}{|c|}{$\%$ Reduction of aflatoxin $B_{1}$ Post radiation } \\
\hline & $4 \mathrm{KGy}$ & $6 \mathrm{KGy}$ & $8 \mathrm{KGy}$ \\
\hline Maize & 15.54 & 32.39 & 60.26 \\
\hline Wheat & 22.25 & 43.84 & 69.29 \\
\hline Rice & 27.46 & 56.38 & 64.68 \\
\hline
\end{tabular}




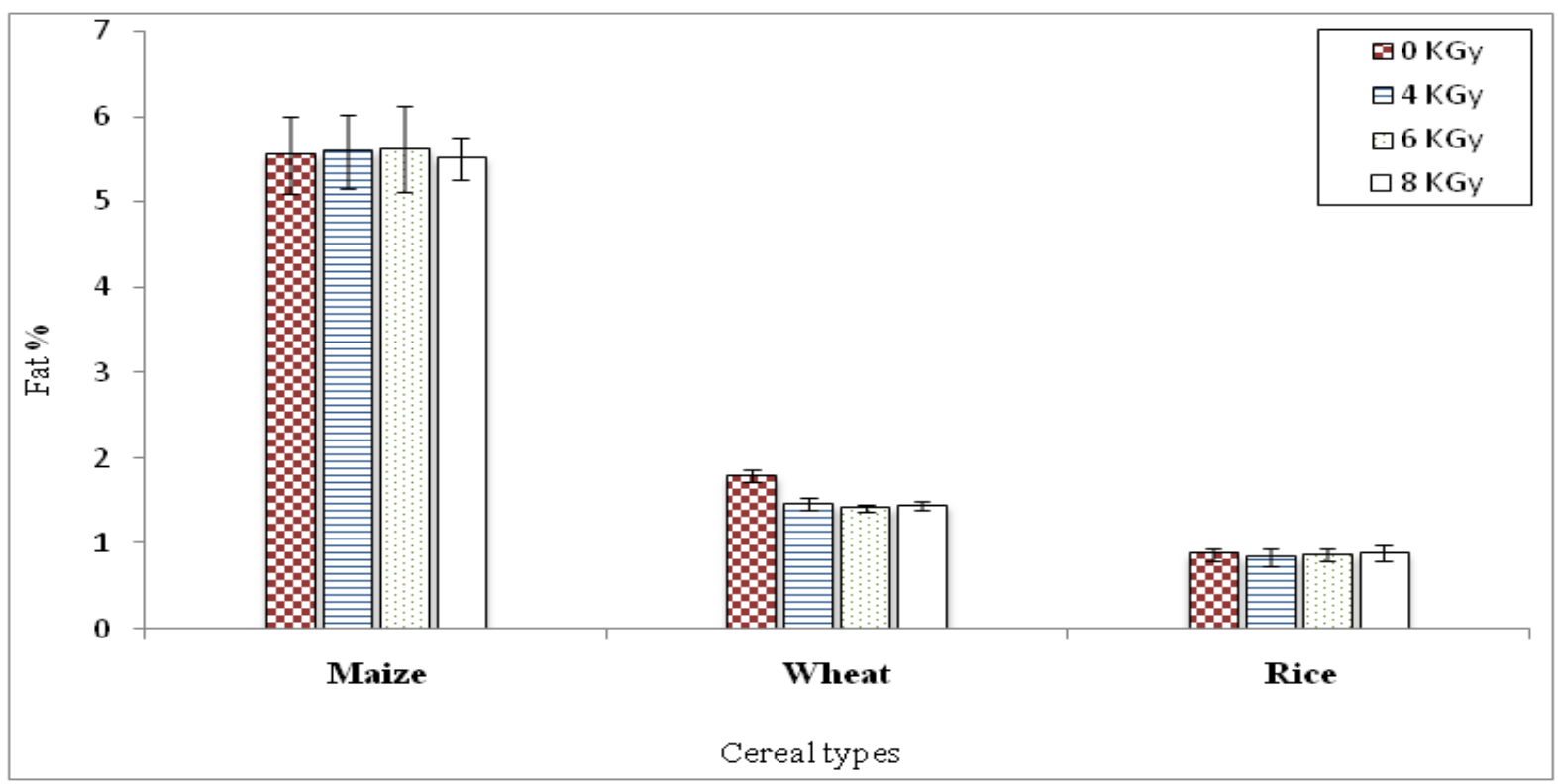

Figure 3. Comparison between the effects of different gamma irradiation doses on fat $\%$ as regard maize, wheat, and rice

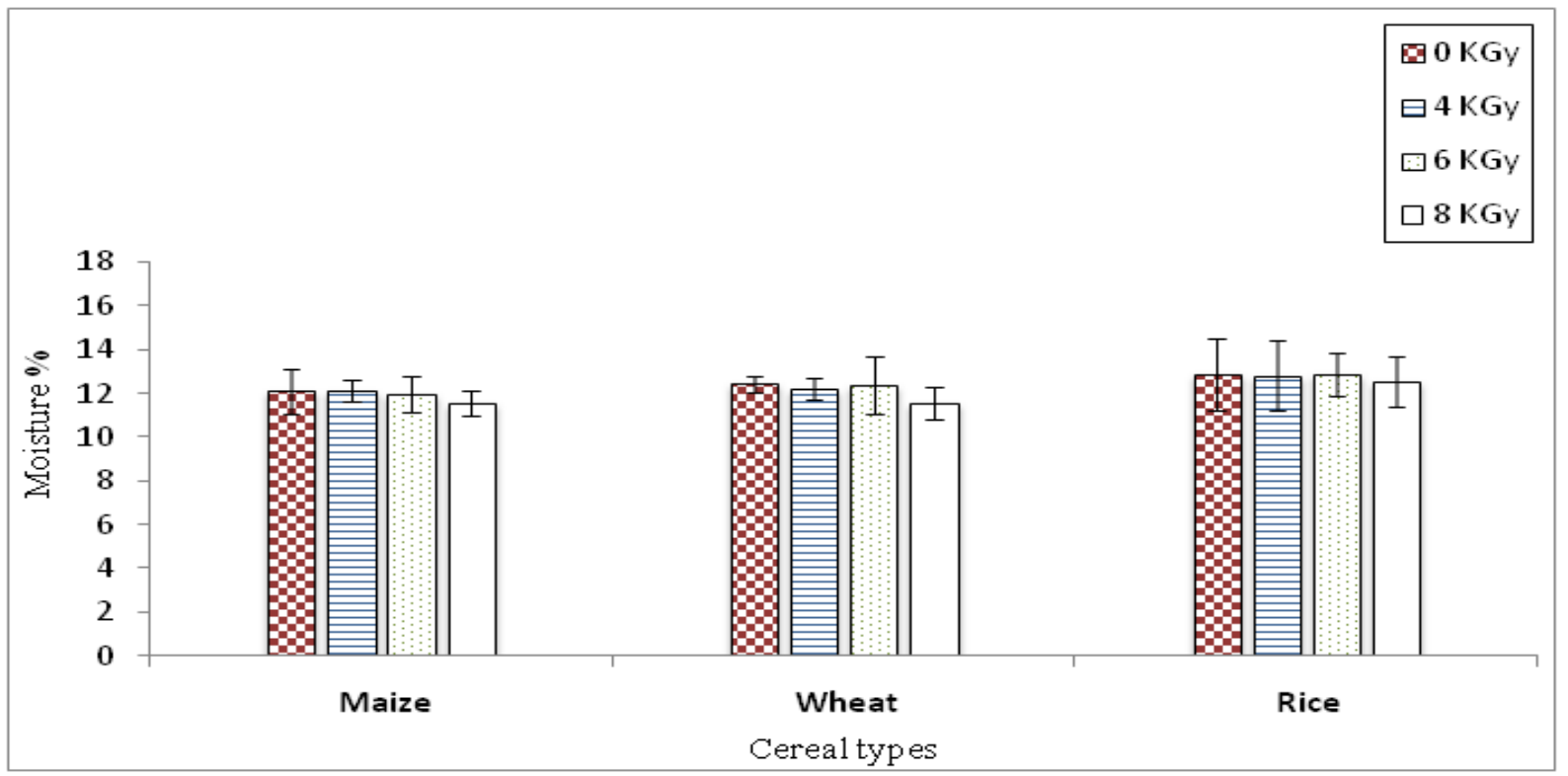

Figure 4. Comparison between the effects of different irradiation doses on mositure\% as regard maize, wheat, and rice

\section{Discussion}

Aflatoxins are secondary metabolites of the common foodborne fungi $A$. flavus and $A$. parasiticus, which colonize crops in tropical and subtropical regions worldwide These fungi can also produce aflatoxin during storage, transportation, and food processing. Aflatoxin contamination primarily occurs in cereals, spices, peanuts, tree nuts (almonds, pistachios, hazelnuts, pecans, and Brazil nuts), and milk. Aflatoxin $\mathrm{B}_{1}$; the most toxic aflatoxin, is the most potent 
naturally occurring chemical liver carcinogen known.[6] $_{\text {[6 }}$

Distribution of aflatoxin $\mathrm{B}_{1}$ in cereal samples (maize, wheat, and rice) was observed in terms of acceptable limit for aflatoxin $\mathrm{B}_{1}$ according to Food and Agriculture Organization (FAO).[7]

From the data presented in Figure 1, it is evident that out of 20 samples of maize about $75 \%$ (15 samples) showed $\mathrm{AFB}_{1}$ concentration greater than $40 \mathrm{ppb}$ (part per billion), about $15 \%$ (3 samples) showed $\mathrm{AFB}_{1}$ concentration in the range between 31 and $40 \mathrm{ppb}, 10 \%$ ( 2 samples) in the range between 21 and $30 \mathrm{ppb}$, and none showed $\mathrm{AFB}_{1}$ concentration less than or equal to $20 \mathrm{ppb}$.

It was found that out of 20 samples of wheat $50 \%$ (10 samples) showed $\mathrm{AFB}_{1}$ concentration more than $40 \mathrm{ppb}, 30 \%$ (6 samples) showed $\mathrm{AFB}_{1}$ concentration between 31 and $40 \mathrm{ppb}$, about $20 \%$ (4 samples) showed $\mathrm{AFB}_{1}$ concentration between 21 and $30 \mathrm{ppb}$ and none showed concentration less than or equal to 20 ppb.

In rice samples it was found that none showed $\mathrm{AFB}_{1}$ concentration more than $40 \mathrm{ppb}, 25 \%$ (5 samples) showed $\mathrm{AFB}_{1}$ concentration between 31 and $40 \mathrm{ppb}, 60 \%$ (12 samples) showed $\mathrm{AFB}_{1}$ concentration between 21 and $30 \mathrm{ppb}$, and 15\% (3 samples) showed aflatoxin concentration less than or equal to $20 \mathrm{ppb}$.

Accordingly, these results indicate that, aflatoxin $\mathrm{B}_{1}$ levels in the collected samples of maize, wheat, and rice are exceeding the acceptable level (5ppb) defined by the FAO.[7]

Tables $1 \& 2$, indicate that before gamma irradiation the order of $\mathrm{AFB}_{1}$ levels in the three grains is maize > wheat > rice and gamma irradiation reduced the toxin significantly with dose levels $8 \mathrm{KGy}>6 \mathrm{KGy}>4 \mathrm{KGy}$. ANOVA test revealed that there is a direct proportionality between the gamma ray dose levels and $\mathrm{AFB}_{1}$ reduction percents.

As indicated in (Figure 3), for maize samples, the initial level of aflatoxin $\mathrm{B}_{1}$ before gamma irradiation is $50.38 \pm 14.46 \mathrm{ng} / \mathrm{g}$ and it reduced to $20.02 \pm 6.70 \mathrm{ng} / \mathrm{g}$ after irradiation (60.26 reduction percent) at a dose level of 8 KGy which is still above the legal limit which is $5 \mathrm{ng} / \mathrm{g}$. For wheat samples the initial level of aflatoxin $\mathrm{B}_{1}$ before irradiation was $37.61 \pm 6.85 \mathrm{ng} / \mathrm{g}$ and reduced to $11.55 \pm 3.41 \mathrm{ng} / \mathrm{g}$ (69.29 reduction percent) after irradiation at the same dose level which is also still above the legal limit which is $5 \mathrm{ng} / \mathrm{g}$ and for rice the initial level of aflatoxin $\mathrm{B}_{1}$ before irradiation was $27.49 \pm 7.32$ $\mathrm{ng} / \mathrm{g}$ it reduced to $9.71 \pm 2.43 \mathrm{ng} / \mathrm{g} \quad(64.68$ reduction percent) after irradiation at a dose level of $8 \mathrm{KGy}$ and it is still above the legal limit which is $5 \mathrm{ng} / \mathrm{g}$.

This means that the percentages of reduction in the levels of aflatoxins were greater in wheat than in rice and maize, respectively, using $8 \mathrm{kGy}$.

On the other hand the reduction percents at 6 KGy are $32.39 \%, 43.84 \%$, and $56.38 \%$ for maize, wheat, and rice respectively, and at $4 \mathrm{KGy}$ the reduction percents are $15.54 \%, 22.25 \%$, and $27.46 \%$ for maize, wheat, and rice, respectively.

From the afford-said data, we concluded that the reduction percentages in aflatoxin $B_{1}$ in the maize, wheat and rice samples are directly proportional to the exposed radiation doses (dose dependent manner) with the highest reduction percent on using the $8 \mathrm{KGy}$ gamma radiation,. Also the reduction percents are different with different cereal samples.

These results are in agreement with the data reported by Aziz and Youssef (2002)[8], who revealed that treatment of food and agricultural products with gamma irradiation at a dose level of $5 \mathrm{KGy}$ destroy $44-48 \%$ of aflatoxin $\mathrm{B}_{1}$ whereas application of $10 \mathrm{KGy}$ dose resulted in reduction of aflatoxin $\mathrm{B}_{1}$ by $82-88 \%$, i.e., our results is nearly consistent with this study in that by increasing the radiation dose the percent of reduction of aflatoxin $B_{1}$ increases.

According to Ghanem et al., (2008)[9], at a dose level of $10 \mathrm{KGy}$ the $\%$ reduction of aflatoxin $\mathrm{B}_{1}$ degradation reached $81.1 \%$ for corn (maize), $87.8 \%$ for rice, and for feed samples aflatoxin reduction levels reached 31,72 , and $84 \%$ in corn at 4, 6, and $10 \mathrm{KGy}$, respectively.

According to Ghanem et al., (2008)[9] study, $\mathrm{AFB}_{1}$ degradation is correlated negatively with oil content in irradiated samples and this is consistent with our study in that aflatoxin $\mathrm{B}_{1}$ reduction level in maize is lower than wheat and rice as maize contains more oil content. 
Also according to Ghanem et al., (2008)[9], there was a positive correlation between the increase in doses of gamma irradiation and the levels of breakdown of $\mathrm{AFB}_{1}$ exist in the commodity and the maximum achievable level of $\mathrm{AFB}_{1}$ break down varied between tested products and this consistent with our study.

Treatment of food with ionizing energy is a well-known method aimed at improving the safety of a wide range of food by reducing or eliminating foodborne pathogens. The results of our work indicated that gamma radiation affect on the moisture content in cereal samples which is in agreement with other investigators.[10,11]

\section{References}

1. Wild C.P., Hall A.J. Primary prevention of hepatocellular carcinoma in developing countries. Mutat. Res. 2000, 462(2-3), 38193. DOI: $10.1016 / \mathrm{S} 1383-5742(00) 00027-2$

2. Anwar W.A., Khaled H.M., Amra H.A., ElNezami H, Loffredo C.A. Changing pattern of hepatocellular carcinoma (HCC) and its risk factors in Egypt: Possibilities for prevention. Mutat. Res .2008, 659, 176-84. DOI: 10.1016/j.mrrev.2008.01.005

3. Paterson R.R.M, Lima N. Further mycotoxin effects from climate change. Food Res Int. 2010,43, 1902-14. DOI: 10.1016/j.foodres.2009.07.010

4. Kozakiewicz Z, Smith D. Physiology of Aspergillus. In: Aspergillus. Smith JE (ed). Plenum Press, New York. 1994;p. 23. DOI: $\underline{10.1007 / 978-1-4615-2411-3 \_2}$
5. Nielsen S. Food analysis laboratory manual. $2^{\text {th }}$ ed. Springer New York Dordrecht Heidelberg London. 2010, p. 20(moisture), 31-2(fat), 41-3( protein), 161-2(fatty acid).

6. International Agency of Research on Cancer, working group on the evaluation of carcinogenic risks to humans. Some traditional herbal medicines, some mycotoxins, naphthalene and styrene. Sheet No 82. Revised 2002.

7. Food and Agriculture Organization. Worldwide regulations for mycotoxins in food and feeds in 2003. FAO Food and Nutrition Paper No 81. Revised 2003.

8. Aziz N.H., Youssef B.M. Inactivation of naturally occurring mycotoxins in some Egyptian foods and agricultural commodities by gamma-irradiation. Egypt J Food Sci 2002, 30, 167-77.

9. Ghanem I, Orfi M, Shamma M. Effect of gamma radiation on the inactivation of aflatoxin $\mathrm{B}_{1}$ in food and feed crops. Braz Journal Microbiol 2008, 39,787-91. DOI: 10.1590/S1517-83822008000400035

10. Aziz N.H., EL-Far F.M., Shahin A.A.M, Roushdy S.M. Control of Fusarium moulds and fumonisin $B_{1}$ in seeds by gammairradiation. Food Control 2007, 18, 1337- 42. DOI: 10.1016/j.foodcont.2005.12.013

11. Stefanova R., Vasilev N.V., Spassov S.L. Irradiation of food, current legislation framework, and detection of irradiated foods. Food Anal. Methods 2010, 3, 225-52. DOI: $\underline{10.1007 / \mathrm{s} 12161-009-9118-8}$ 